\title{
ESR DATING OF MARINE BARITE IN CHIMNEYS DEPOSITED FROM HYDROTHERMAL VENTS
}

\author{
TASUKU OKUMURA ${ }^{1}$, SHIN TOYODA ${ }^{1}$, FUMIHIRO SATO $^{1}$, AI UCHIDA ${ }^{1}$, \\ JUN-ICHIRO ISHIBASHI ${ }^{2}$ and SHUN'ICHI NAKAI ${ }^{3}$ \\ ${ }^{1}$ Department of Applied Physics, Okayama University of Science, 1-1 Ridai-cho, Kita-ku, Okayama 700-0005, Japan \\ ${ }^{2}$ Department of Earth and Planetary Sciences, Kyushu University, 6-10-1 Hakozaki, Higashi-ku, Fukuoka 812-8581, Japan \\ ${ }^{3}$ Earthquake Research Institute, The University of Tokyo, 1-1-1, Yayoi, Bunkyo-ku, Tokyo 113-0032, Japan
}

Received 17 February 2010

Accepted 14 July 2010

\begin{abstract}
Electron Spin Resonance (ESR) dating of marine barite in chimneys deposited from hydrothermal vents was attempted to determine the time since hydrothermal activity occurred. In this study, we used Barite $\left(\mathrm{BaSO}_{4}\right)$ precipitated in icroenvironments in the chimneys deposited from the hydrothermal vents at the Archaean site in South Mariana spreading centre $\left(12^{\circ} 56.4^{\prime} \mathrm{N}, 143^{\circ} 37.9^{\prime} \mathrm{E}\right)$ and at Hakurei site in the Izena caldron $\left(27^{\circ} 15^{\circ} \mathrm{N}, 127^{\circ} 04^{\circ} \mathrm{E}\right)$ for ESR measurements. ESR spectrum of marine barite is characterized by an electron-type centre with g values of 2.0034, 2.0022 and 1.9995 attributed to $\mathrm{SO}_{3}{ }^{-}$. The signal intensity increased with gamma ray dose. The dose rates of hydrothermal chimneys from the Archaean site and from the Hakurei site were calculated using a model that assumed a grain size and that incorporation of radionuclides after ${ }^{226} \mathrm{Ra}$ in $\mathrm{U}$ series into the chimney, and assuming the efficiency of the defect formation by alpha particles to be the same as that for OSL. The ESR ages were estimated to be 470 years old for barite from the Archaean site and 5670 years old for one from the Hakurei site, although there is a considerable difference between the present ESR ages and the ${ }^{210} \mathrm{~Pb} /{ }^{226} \mathrm{Ra}$ disequilibrium ages previously reported.
\end{abstract}

Keywords: marine barite, ESR, dating, hydrothermal chimney

\section{INTRODUCTION}

At the beginning of the discovery of the hydrothermal systems in the sea, their timescales were not of interest. The timescale became one of the issues when some huge hydrothermal plumes were found along with volcanic activities at the sea floor and sudden changes in the hydrothermal activities were reported. The long-term change of the hydrothermal activities also became of interest in the aspect of ore formations (e.g. Urabe, 1995). However, no systematic geochronological studies of the hydrothermal system at the sea floor have been possible so far due to lack of methods that cover the age ranges of interest. Recently, water circulation below the sea floor and the chemical interaction of sea water and fluid related with the hydrothermal activities have been a subject of the scientific study to investigate the transfer of the elements from the magma to the sea water and to inform on the biological systems sustained by the chemical species in those water flows (e.g. Macdonald et al., 1980).

Corresponding author: S. Toyoda

e-mail: toyoda@dap.ous.ac.jp

ISSN 1897-1695 (online), 1733-8387 (print) @ 2010 GADAM Centre, Institute of Physics, Silesian University of Technology.

All rights reserved.
Electron Spin Resonance (ESR) dating studies on oceanic materials have been limited to corals (e.g. Ikeda et al., 1992; Schellmann et al., 2004), shells (e.g. Radtke et al., 1982; Molodkov, 2001) and foraminifera (Sato, 1982; Mudelsee et al., 1992) as summarized by Ikeya (1993). These materials are useful for the studies on sea level change and related tectonic activities. However, no ESR studies on hydrothermal ore deposits in deep-sea floor have been reported so far.

Barite $\left(\mathrm{BaSO}_{4}\right)$, the most common barium mineral, occurs in depositional environments on sea floor, as well as in those on land including biogenic, hydrothermal, and evaporation on land. There were several ESR studies on the signals of barite (Ryabov et al., 1983) where Kasuya et al. (1991) suggested that barite is a mineral possibly suitable for ESR dating as indicated by the dose response and the thermal stability of the signal. However, so far there have been no reports on practical ESR dating of barite.

In this study, electron spin resonance (ESR) investigation of marine barite was carried out to evaluate its use as a dating for the evolution of hydrothermal systems, which 
are directly related to ore formation and to life activities in the sea floor.

\section{SAMPLES}

Two inactive chimney samples deposited from hydrothermal vents at different troughs of the see-floor were selected in this study.

Chimney 903-R7 from the South Mariana Trough was collected during the YK05-09 cruise, which was conducted in July and August 2005, by deep-sea submersible vehicle Shinkai 6500 performed by the Japan Agency for Marine-Earth Science and Technology (JAMSTEC). The sample was collected during dive 903 at the Archaean site $\left(12^{\circ} 56.4^{\prime} \mathrm{N}, 143^{\circ} 37.9^{\prime} \mathrm{E}\right.$; depth $3,000 \mathrm{~m}$ ) (Ishibashi et al., 2006). This chimney mainly comprises barite, spharelite and pyrite. The age of this chimney has been estimated to be $31.1 \pm 1.5$ years before 2005 using the ${ }^{210} \mathrm{~Pb} /{ }^{226} \mathrm{Ra}$ disequilibrium method (Noguchi, 2007).

Chimney 220 was collected at Hakurei site $\left(27^{\circ} 15^{\circ} \mathrm{N}\right.$, $\left.127^{\circ} 04^{\circ} \mathrm{E}\right)$ in the Izena caldron, Okinawa Trough by ROV Hyper-Dolphin (dive 220) during the NT03-09 cruise performed by JAMSTEC in July and August 2003. This chimney mainly comprises barite, spharelite, pyrite and traces of sulfide bearing antimony and arsenic. The age of this chimney has been estimated to be 24-33 years before 2005 using the ${ }^{210} \mathrm{~Pb} /{ }^{226} \mathrm{Ra}$ disequilibrium method (Noguchi, 2007).

Chimney samples were cut into slice perpendicular to the growth orientation. Samples numbered 903-R7-2 and 220-E (see Noguchi, 2007) were used in this study.

\section{EXPERIMENTAL PROCEDURES}

Barite was separated from the chimney using a sequential leaching procedure. Approximately 2 g (dry weight) of a fragment hewed from core of chimney sample approx. $14 \mathrm{~cm}$ in diameter, was crushed using a mortar and placed in a $300 \mathrm{ml}$ beaker. To separate sulfides from the chimney, the sample was treated by $20 \mathrm{ml}$ of $12 \mathrm{M} \mathrm{HCl}$ for $24 \mathrm{~h}$ at room temperature. Then sulfides as sphalerite and pyrite were removed from the residue by treating it with $10 \mathrm{ml}$ of $13 \mathrm{M} \mathrm{NHO}$ for $24 \mathrm{~h}$ at room temperature. The residue then was leached by $10 \mathrm{ml}$ of $6 \mathrm{M} \mathrm{HCl}$ and $10 \mathrm{ml}$ distilled water. The sample was dried using heater at $40^{\circ} \mathrm{C}$ and then sieved to obtain a $75-300$ $\mu \mathrm{m}$ grain fraction. The sample was analyzed using X-ray diffraction (XRD) and Scanning Electron MicroscopeEnergy Dispersive X-ray System (SEM-EDS) at Okayama University of Science after the impurities such as remaining sulfide, were handpicked and removed. Extracted barite was $\sim 30-35 \%$ in weight percent of a chimney sample.

All samples were measured with a JEOL PX-2300 ESR spectrometer at Okayama University of Science. The measurement was carried out under following conditions; microwave power $1 \mathrm{~mW}$, width of the magnetic field $10 \mathrm{mT}$ scanned in $1 \mathrm{~min}$. with accumulation of 5 scans, modulation amplitude $0.1 \mathrm{mT}$, modulation frequency of $100 \mathrm{kHz}$, time constant $0.03 \mathrm{~s}$ at room temperature.
The dose response of ESR signals in barite was obtained by irradiating the samples using a ${ }^{60} \mathrm{Co}$ gamma ray source at doses ranging from approx. 50 to $2600 \mathrm{~Gy}$ at a dose rate of approx. $100 \mathrm{~Gy} / \mathrm{h}$ at Takasaki Advanced Radiation Research Institute of Japan Atomic Energy Agency. ESR measurements were made about a week storage after the irradiation.

In order to estimate dose rate for the chimney samples, at first two-dimensional measurement of radiation produced by natural irradiation of the chimney was performed by the use of an imaging plate (for more details see Hareyama et al., 2000; Toyoda et al., 2010) and then radionuclide concentrations of $U$ and Th series, and potassium $\left(\mathrm{K}_{2} \mathrm{O}\right)$ were measured using gamma-ray spectrometry at Okayama University of Science with a low background germanium semiconductor detector system (CANBERRA GC1520).

\section{RESULTS AND DISCUSSION}

\section{ESR signals}

ESR spectra of marine barites in 903-R7-2 from the South Mariana Trough and in 220-E from Izena caldron, Okinawa, at room temperature, are shown in Figs. 1 and 2 , respectively. A set of signals is observed in both samples. The observed signal is attributed to the electronic $\mathrm{SO}_{3}{ }^{-}$centre (Ryabov et al., 1983; Kasuya et al., 1991) with a structure similar to the $\mathrm{E}^{\prime}$ centre in $\mathrm{SiO}_{2}$ and $\mathrm{CO}_{2}{ }^{-}$ centre in $\mathrm{CaCO}_{3}$ (Kasuya et al., 1991). The $\mathrm{g}$ factors are $2.0034,2.0022$, and 1.9995, and are consistent with those reported by Ryabov et al. (1983), 2.0032, 2.0023, and 1.9995. The ESR intensity of $\mathrm{SO}_{3}{ }^{-}$centre in both samples was enhanced by gamma irradiation of approx. $2000 \mathrm{~Gy}$ as shown in Figs. 1 and 2. The shapes of two curves did not change by irradiation. However, o hole-type $\mathrm{O}_{2}{ }^{3-}$ centre $(\mathrm{g}=2.0191,2.0127$, and 2.0103 reported by Kasuya et al., 1991) was detected in either sample. The $\mathrm{O}_{2}{ }^{3-}$ centre observed in anhydrite $\left(\mathrm{CaSO}_{4}\right)$ is stabilized by a

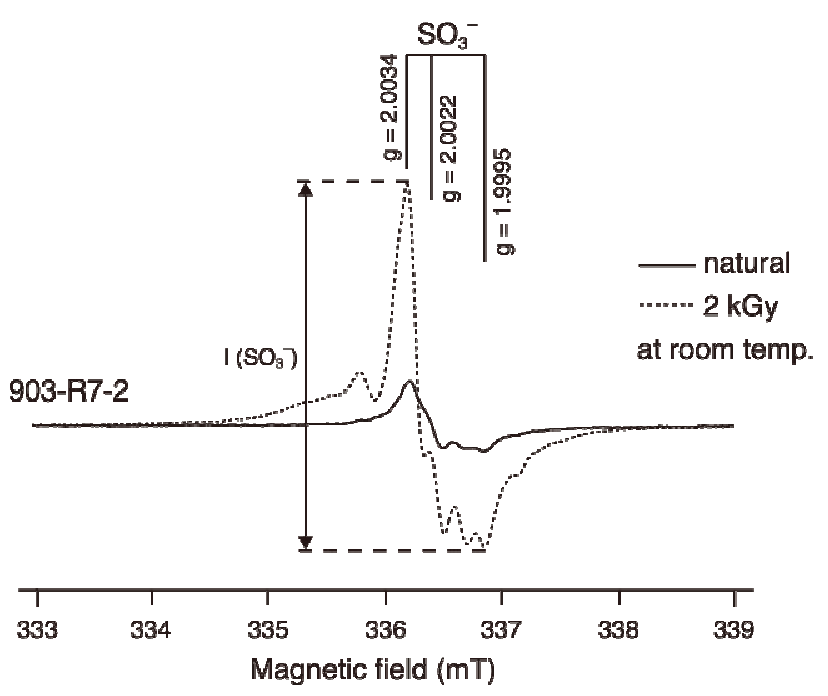

Fig. 1. The ESR spectra due to $\mathrm{SO}_{3}^{-}$observed in a marine barite sample, 903-R7 chimney, solid line is for natural sample and broken line after irradiation. I denotes the intensity of the $\mathrm{SO}_{3}{ }^{-}$signal, peak height between $g=2.0034$ and $g=1.9995$. 


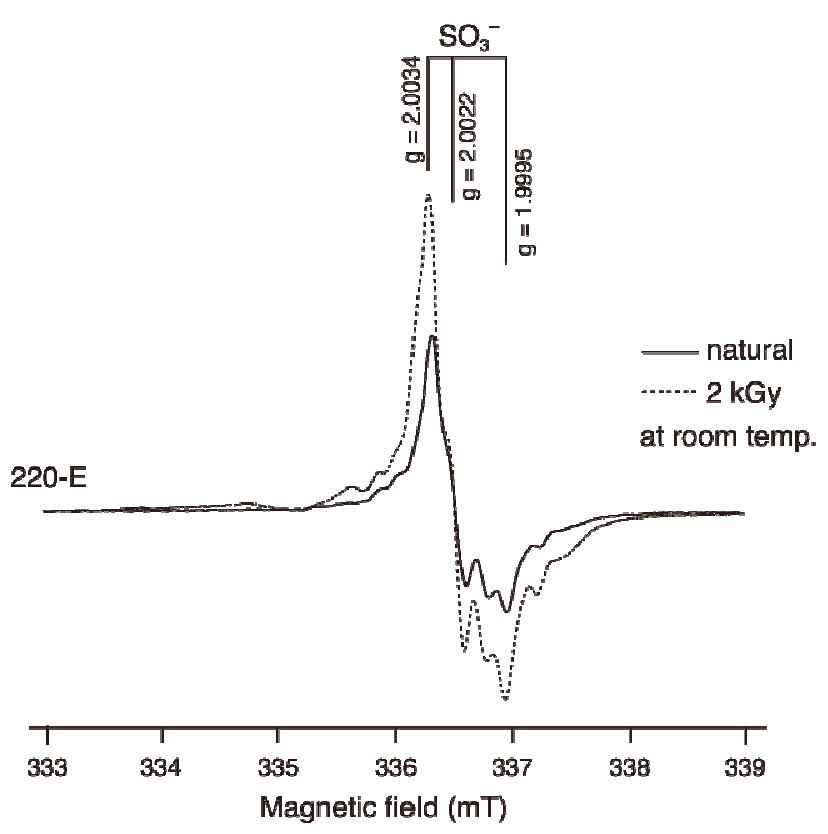

Fig. 2. The ESR spectra due to $\mathrm{SO}_{3}^{-}$observed in a marine barite sample, 220-E chimney, solid line is for natural sample and broken line after irradiation. I denotes the intensity of the $\mathrm{SO}_{3}{ }^{-}$signal, peak height between $g=2.0034$ and $g=1.9995$.

trivalent metallic ion $\left(\mathrm{M}^{3+}\right)$ such as $\mathrm{Y}^{3+}$ (Bershov et al., 1971). Therefore, the contents of a $\mathrm{M}^{3+}$ ion in marine barite may be different from that in natural barite on land.

\section{Dose response}

In this study, the amplitude between the peaks at $\mathrm{g}=$ 2.0034 and $g=1.9995$ was taken as the intensities of the $\mathrm{SO}_{3}{ }^{-}$signal. Additive dose responses for the two samples are shown in Figs. 3 and 4. The intensities were enhanced at least up to approx. $2600 \mathrm{~Gy}$. According to Kasuya et al. (1991), the thermal annealing experiment indicated that these electron-type centres in barite are stable up to $330^{\circ} \mathrm{C}$ and more stable than the hole-type centres. Moreover, they reported that the electron centres could be applicable to ESR dating.

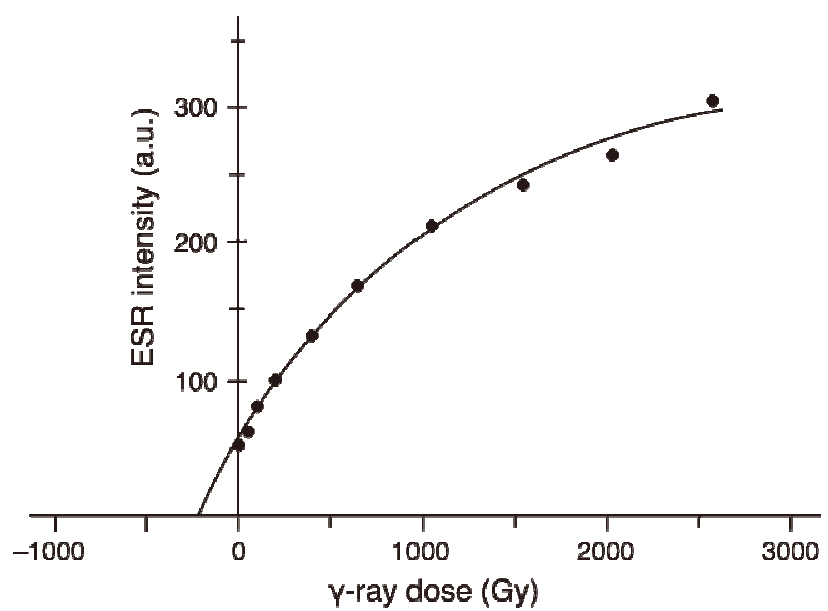

Fig. 3. Dose response curve of the $\mathrm{SO}_{3}^{-}$signal fitted to a saturating exponential function for marine barite in chimney 903-R7-2.
The dose responses were fitted to a saturating exponential function to extrapolate the curve to the zero ordinate in order to determine the equivalent doses $\left(D_{e}\right)$. For each sample, $\mathrm{D}_{\mathrm{e}}$ values were obtained to be $231 \mathrm{~Gy}$ for 903-R7-2 and 1730 Gy for 220-E as shown in Table 1. The errors of $D_{e}$ 's were calculated by considering the errors of the parameters of the saturating exponential curves and the correlation between the errors. The reproducibility of the signal on repeated measurements was about $5 \%$. One could see a possible kink at the middle of the dose responses. This issue should be one of the topics to be further investigated whether a single saturation exponential curve is appropriate for fitting the dose responses of the barite signal.

\section{Distribution of radioactive elements}

Polarized microscopic observation of thin section sample was conducted, and then the distribution of radioactivity in samples was examined with an imaging plate (Toyoda et al., 2010). A typical example of natural radioactivity mapping of core part of chimney 903-R7-2 sample is shown in Fig. 5. The darker areas in Fig. 5c correspond to those with relatively higher radioactivity. As a result of comparing autoradiograph with optical microphotograph, it was confirmed that radioactive sources within the chimney corresponds to marine barite (bright area in Fig. 5b and dark area in Fig. 5c) where the barite is strewn in the whole sample (Fig. 5a). The shape of marine barite is a rectangle and its grain size is approx. $100 \times 40 \times 20 \mu \mathrm{m}$ in the core of the sample. In this study, we used barite in the core part of the sample rather than those in the vein. The ${ }^{226} \mathrm{Ra}$ activities of the barite were measured by gamma ray spectrometry assuming radioactive equilibrium. The bulk Ra concentrations were 7.72 $\mathrm{Bq} / \mathrm{g}$ for chimney 903-R7-2 and 4.77 Bq/g for chimney 220-E, while the decay members of Th series and $\mathrm{K}_{2} \mathrm{O}$ were not detected.

For the above observation, we considered how much energy of $\alpha, \beta$ and $\gamma$ ray emitted from barite is absorbed within the sample based on a model that a grain of barite is an infinite plate (layer) with $20 \mu \mathrm{m}$ in thickness. The range of alpha particles in barite of density of $4.5 \mathrm{~g} / \mathrm{cm}^{3}$

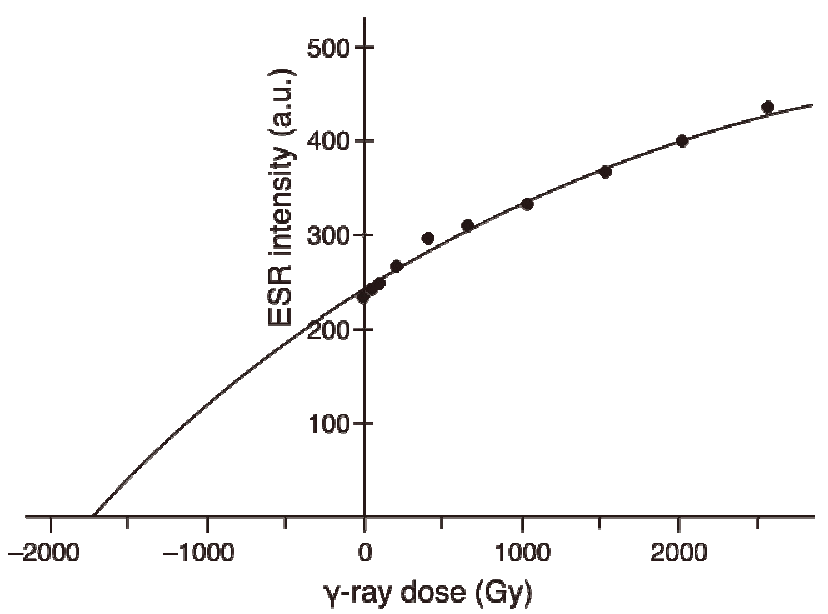

Fig. 4. Dose response curve of the $\mathrm{SO}_{3}{ }^{-}$signal fitted to a saturating exponential function for marine barite in chimney 220-E. 
was calculated to be approx. 7.2 $\mu \mathrm{m}$. The internal alphadose was calculated to be 0.8 times the value for infinite media where the attenuation factor was obtained from the Fig. A-1 of Grün (1989) after correcting for the difference in density; the density of barite is $4.5 \mathrm{~g} / \mathrm{cm}^{3}$ while that of quartz is $2.7 \mathrm{~g} / \mathrm{cm}^{3}$. The internal beta dose in barite was estimated to be $5 \%$ of the value for infinite media, according to Grün (1987) estimation for hydroxyapatite (density: $2.95 \mathrm{~g} / \mathrm{cm}^{3}$ ) in a layer. The external $\beta$ ray dose was estimated to be reduced by $5 \%$ where the external $\beta$ ray dose was calculated from the Ra concentration averaged over the whole sample. In order to evaluate the effect of gamma dose within the chimney, we estimated the amount of gamma dose contribution to the central portion of sample. The $\gamma$ ray dose exponentially decreases with distance. The half-thickness for the absorption of $\gamma$ ray was estimated from that in aluminum (Firestone and Shirley, 1996), which is $2.2 \mathrm{~cm}$ after correcting for the difference in density. It is necessary to estimate the missing contribution of $\gamma$ ray which come from the outside more than $7 \mathrm{~cm}$ to the sample in central $2 \mathrm{~cm}$ hewed out from the core of the chimney $\sim 14 \mathrm{~cm}$ in diameter. After integrating the exponential function, we calculated this contribution to be $11 \%$. Therefore, the gamma ray dose was estimated to be $89 \%$ of value for infinite media. The cosmic ray dose was assumed to be negligible because of sample on the sea floor at a depth $\sim 3000 \mathrm{~m}$ under water. The doses from $\mathrm{Th}$ and $\mathrm{K}$ were also negligible and hence not considered. As results, the natural dose rates were calculated to be $493 \mathrm{mGy} / \mathrm{y}$ for chimney 903-R7-2 and $305 \mathrm{mGy} / \mathrm{y}$ for chimney 220-E (Table 1). In this estimation, the conversion factors proposed by Adamiec and Aitken (1998) were used after subtracting the contribution from ${ }^{238} \mathrm{U}$ to ${ }^{230} \mathrm{Th}$. The efficiency of the defect formation by alpha particles was assumed to be 0.1 (Aitken, 1998) which is the case for luminescence in quartz to be 0.25 (Nagar et al., in press) which is the case for the ESR signal in gypsum.

\section{ESR ages}

ESR ages of hydrothermal chimney 903-R7-2 and 220-E are listed in Table 1. The age of chimney 903-R72 from Archaean site, South Mariana Trough was computed to be $300-470$ years. This is to be contrasted with an estimate of $31.1 \pm 1.5$ years before 2005, using ${ }^{210} \mathrm{~Pb} /{ }^{226} \mathrm{Ra}$ disequilibrium method (Noguchi, 2007). ESR age is approx. 10-15 times older. For the chimney 220-E from the Hakurei site, Izena caldron, ages of 3620-5670 years old were calculated from ESR dating. However, Noguchi (2007) reported that the ${ }^{210} \mathrm{~Pb} /{ }^{226} \mathrm{Ra}$ age ranges from 24 to 33 years before 2005. ESR age is approx. 100200 times older than that by the ${ }^{210} \mathrm{~Pb} /{ }^{226} \mathrm{Ra}$ disequilibrium method. The results presented in the current study show that ESR ages of chimney are systematically, orders of magnitude older than those obtained by ${ }^{210} \mathrm{~Pb} /{ }^{226} \mathrm{Ra}$ method.

There could by several reasons for the discrepancy, especially those relating to dose rate estimation. The estimation of dose rates for $\alpha, \beta$ and $\gamma$ in this study is based on model considering the grain size of actual barite in chimney core as plate-like crystal grain of $20 \mu \mathrm{m}$ thickness. As our preliminary results for ${ }^{230} \mathrm{Th} /{ }^{234} \mathrm{U}$ in sulfide minerals indicate, the age of chimney 903-R7 to be in the range of 2000-3000 years. If this result is right, we still raise an additional issue of whether the ${ }^{210} \mathrm{~Pb} /{ }^{226} \mathrm{Ra}$ disequilibrium system works for marine barite. Dating of marine barite leaves therefore an open issue to be investigated by every possible dating method.

The present results, first practical application of ESR dating method to barite, showed that the ESR signal, electronic $\mathrm{SO}_{3}{ }^{-}$centre, in marine barite could be used to deduce the age of hydrothermal deposit on the sea floor. However, in order to conduct practical ESR dating, further work is needed to pursuit how to calculate dose rate for $\alpha, \beta$ and $\gamma$ rays in hydrothermal chimney. The efficiency of the defect formation by alpha particles in barite is another factor to be estimated by experimental He ion
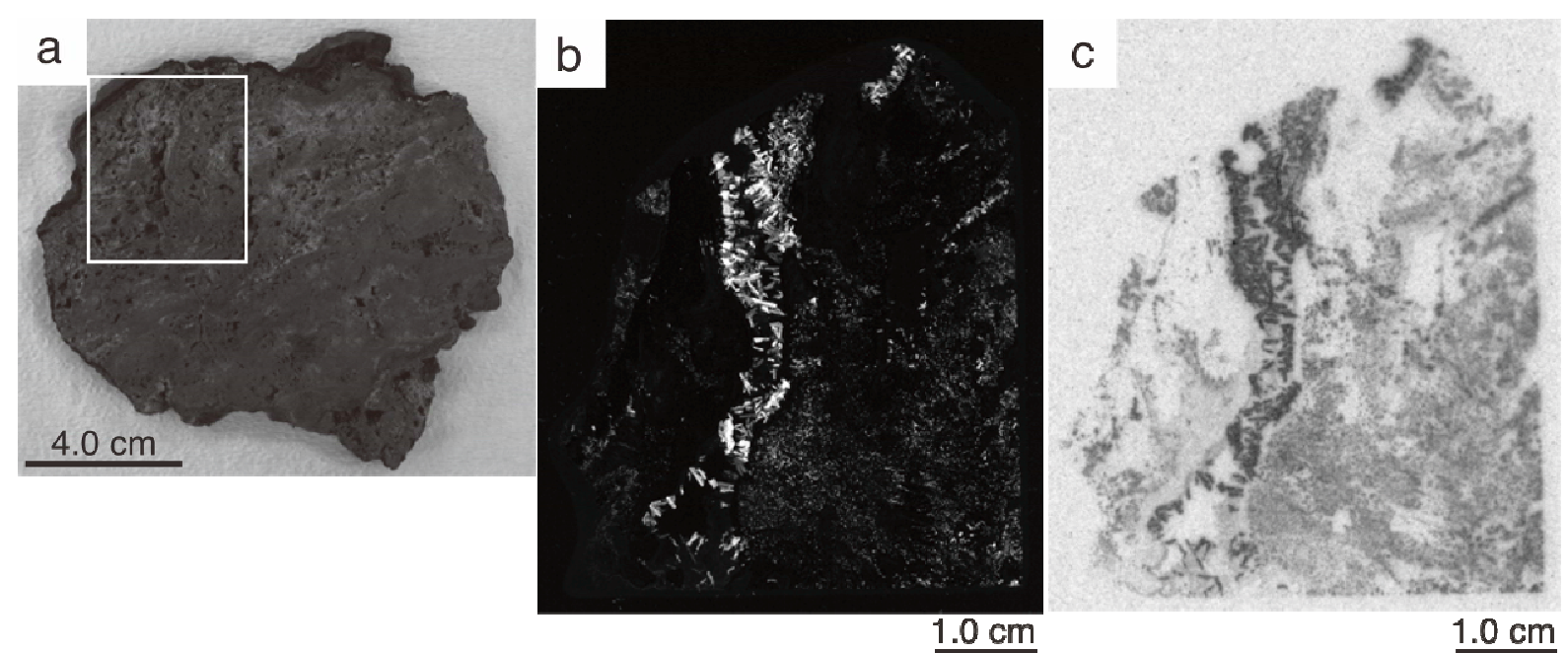

Fig. 5. Images taken for chimney 903-R7-2. (a) Photograph of the whole cross section. Grains and crystals representing white are barite and those of black are spharelite and pyrite. (b) Polarized microscope of optical microphotograph. (c) Distribution of natural radioactivity of polished thin section of area outlined in cross-section photograph of chimney obtained by an imaging plate and Fuji BAS 1800Il, a red-out device. The dark areas correspond to areas with relatively high content of radioactivity. 
Table 1. Results of the present analysis of ESR dating.

\begin{tabular}{|c|c|c|c|c|c|c|c|c|}
\hline \multirow{2}{*}{$\begin{array}{l}\text { Sample } \\
\text { No }\end{array}$} & \multirow{2}{*}{$\begin{array}{c}\mathrm{Ra} \\
\text { Concentration* } \\
(\mathrm{Bq} / \mathrm{g})\end{array}$} & \multirow{2}{*}{$\begin{array}{l}\text { Equivalent } \\
\text { Dose } \\
D_{e}(G y)\end{array}$} & \multicolumn{4}{|c|}{ Dose rate (mGy/y) } & \multirow{2}{*}{ Age (1) } & \multirow{2}{*}{ Age (2) } \\
\hline & & & $D_{a}(1)$ & $D_{a}(2)$ & $D_{\beta}$ & $D_{y}$ & & \\
\hline 903-R7-2 & 7.72 & $231 \begin{array}{l}+33 \\
-29\end{array}$ & 186 & 465 & 123 & 184 & $470 \pm 60$ & $300 \pm 40$ \\
\hline $220-E$ & 4.77 & $1730 \begin{array}{l}+320 \\
-240\end{array}$ & 15 & 288 & 76 & 114 & $5670 \begin{array}{l}+1060 \\
-770\end{array}$ & $\begin{array}{ll}3620 & +680 \\
-490\end{array}$ \\
\hline
\end{tabular}

${ }^{*}$ Bulk Ra concentration

The alpha efficiency is assumed to be (1) 0.1 and (2) 0.25 .

implantation test. In addition, inhomogeneity of dose rate, the accumulated dose within a chimney sample could also affect the dose rate estimation. Internal consistency check, with several pieces from a same chimney sample would also be desirable.

\section{CONCLUSIONS}

In order to evaluate the date for the evolution of a hydrothermal system in the sea floor, the preliminary study of ESR dating using marine barite from chimney deposited from hydrothermal vent in the sea floor was carried out. ESR signal attributed to an electronic $\mathrm{SO}_{3}{ }^{-}$ centre was observed in marine barite from the Archaean site in South Mariana spreading centre and at Hakurei site in the Izena caldron. The signal intensities in both samples was enhanced up to 2600 Gy with gamma ray dose. The ESR age of was tentatively estimated to be 300-470 years old for barite from the Archaean site and 3620-5670 years old for the Hakurei site. However, the ESR ages differed substantially from the ${ }^{210} \mathrm{~Pb} /{ }^{226} \mathrm{Ra}$ disequilibrium ages previously reported. Further basic studies are needed to establish the ESR dating method for barite formed by hydrothermal activity.

\section{ACKNOWLEDGEMENTS}

This work has been supported by a Grant-in-Aid for Scientific Research on Innovative Areas "TAIGA" of the Ministry of Education, Culture, Sports, Science and Technology (MEXT), Japan and by the Inter-University Program for the Common Use of the Japan Atomic Energy Research Institute (JAERI) Facilities, Japan.

\section{REFERENCES}

Adamiec G and Aitken M, 1998. Dose-rate conversion factors: update. Ancient TL 16: 37-50.

Aitken M, 1998. An Introduction to Optical Dating. Oxford Science Publications, Oxford, 267pp.

Bershov LV, Martirosyan VO, Marfunin AS and Speranskii AV, 1971. The yttrium-stabilized electron-hole centres in anhydrite. Physica Status Solidi (b) 44: 505-512.

Firestone RB and Shirley VS. eds., 1996. Table of Isotopes. Eighth edition. Toronto, John Wiley and Sons Inc., G-2: 2877pp.

Grün R, 1989. Electron spin resonance dating. Quaternary International 1: 65-109, DOI 10.1016/1040-6182(89)90010-4.

Hareyama M, Tsuchiya N, Takebe M and Chida T, 2000. Twodimensional measurement of natural radioactivity of granitic rocks by photostimulated luminescence technique. Geochemical Journal 34: 1-9.

Ikeda S, Kasuya M, Ikeya M, 1992. ESR dating of corals and reannealing effects on ESR signals. Quaternary Science Reviews, 11: 203-207, DOI 10.1016/0277-3791(92)90064-F.

Ikeya M, 1993. New applications of electron spin resonance: dating, dosimetry and microscopy. Singapore, World Scientific: 500pp.

Ishibashi J, Suzuki R, Yamanaka T, Toki T, Kimura H, Noguchi T and Urabe T, 2006. Seafloor hydrothermal activity at off-axial seamounts of backarc spreading in southern Mariana Trough. Geochimica et Cosmochimica Acta 70: A279, DOI 10.1016/j.gca.2006.06.566.

Kasuya M, Kato M and Ikeya M, 1991. ESR signals of natural barite $\left(\mathrm{BaSO}_{4}\right)$ crystals: possible application to geochronology. Essay in Geology, Prof. Nakagawa Commemorative Volume: 95-98.

Macdonald KC, Becker K, Speiss FN and Ballard RD, 1980. Hydrothermal heat flux of the "black smoker" vents on the East Pacific Rise. Earth and Planetary Science Letters 48: 1-7, DOI 10.1016/0012-821X(80)90163-6.

Molodkov A, 2001. ESR dating evidence for early man at a Lower Palaeolithic cave-site in the Northern Caucasus as derived from terrestrial mollusc shells. Quaternary Science Reviews 20: 10511055, DOI 10.1016/S0277-3791(00)00044-5.

Mudelsee M, Barabas M and Mangini A, 1992. ESR dating of the quaternary deep-sea sediment core RC17-177. Quaternary Science Reviews 11: 181-189, DOI 10.1016/0277-3791(92)90061-C.

Nagar YC, Sastry MD, Bhushan B, Kumar A, Mishra KP, Shastri A, Deo MN, Kocurek G, Magee JW, Wadhawan SK, Juyal N, Pandian MS, Shukla AD, Singhvi AK (in press) Chronometry and formation pathways of gypsum using Electron Spin Resonance and Fourier Transform Infrared Spectroscopy. Quaternary Geochronology 5(6): 691-704, DOI 10.1016/j.quageo.2010.05.001.

Noguchi T, 2007. Geochemical studies on the deep and shallow submarine hydrothermal activities. $\mathrm{PhD}$ thesis, University of Ryukyu: $123 \mathrm{pp}$ (in Japanese, abstract in English).

Radtke T, Mangini A, Grün R, 1982. ESR dating of marine fossil shells. Nuclear Tracks and Radiaion. Measurements 10: 879-884, DOI 10.1016/0735-245X(85)90103-6.

Ryabov ID, Bershov LV, Speranskiy AV and Ganeev IG, 1983. Electron paramagnetic resonance of $\mathrm{PO}_{3}{ }^{2-}$ and $\mathrm{SO}_{3}{ }^{-}$radicals in barite. Physics and Chemistry of Minerals 10: 21-26, DOI 10.1007/BF00199558.

Sato T, 1982. ESR dating of planktonic foraminifera. Nature 300: 518. DOI 10.1038/300518a0.

Schellmann G, Radtke U, Scheffers A, Whelan F and Kelletat D, 2004. ESR Dating of Coral Reef Terraces on Curaçao (Netherlands Antilles) with Estimates of Younger Pleistocene Sea Level Elevations. Journal of Coastal Research 20(4): 947-957, DOI 10.2112/02101.1

Toyoda S, Hino Y, Romanyukha AA, Tarasov O, Pivovarov SP and Hoshi M, 2010. ${ }^{90} \mathrm{Sr}$ in mammal teeth form contaminated areas in the former Soviet Union measured by imaging plates. Health Physics 98: 352-359, DOI 10.1097/01.HP.0000346705.98995.e7.

Urabe T, 1995. Sea-floor Hydrothermal Activities in Western Pacific and their Relation to Ancient Volcanogenic Massive Sulfide Mineralization. Journal of geography 104: 438-448 (in Japanese). 